\title{
Form Quality in Rorschach Comprehensive System and R-PAS: Sample of Psychiatric Cases ${ }^{1}$
}

\author{
Latife Yazigi ${ }^{2}$ \\ Universidade Federal de São Paulo, \\ São Paulo-SP, Brazil \\ Roberta Katz Abela \\ Universidade Federal de São Paulo, \\ São Paulo-SP, Brazil
}

\author{
Norma Lottenberg Semer \\ Universidade Federal de São Paulo, \\ São Paulo-SP, Brazil \\ Tatiana Gottlieb Lerman \\ Universidade Federal de São Paulo, \\ São Paulo-SP, Brazil
}

\author{
Maria Luiza de Matos Fiore \\ Universidade Federal de São Paulo, \\ São Paulo-SP, Brazil \\ Thaís Cristina Marques \\ Universidade Federal de São Paulo, \\ São Paulo-SP, Brazil
}

\begin{abstract}
The creation of the Rorschach Performance Assessment System (R-PAS) requires research that allows its use in the Brazilian population. The Formal Quality (FQ) category is essential both for clinic and research. The aim of this study was to compare form quality variables in Rorschach protocols from psychiatric patients and ratings coded in the Comprehensive System (CS) and R-PAS. The sample comprised 206 Rorschach protocols from adult patients in psychiatric treatment, who were also assessed by SCID-I and SCID-II. Most protocols were administered in the CS and recoded according to the R-PAS. The kappa coefficient was calculated, and we compared the means of these variables in both systems. The kappa results varied from almost perfect to substantial consistency for all variables, however, the descriptive statistics confirmed that the R-PAS elicits more FQ ordinary coding while the CS elicits more FQ minus coding.
\end{abstract}

Keywords: psychological assessment, Rorschach test, projective techniques, psychiatric patients

\section{Qualidade Formal do Rorschach Sistema Compreensivo e R-PAS: Amostra de Casos Psiquiátricos}

\begin{abstract}
Resumo: A criação do Sistema de Avaliação de Desempenho do Rorschach (R-PAS) requer estudos que possibilitem o uso na população brasileira. A qualidade formal (FQ) é uma categoria imprescindível na clínica e na pesquisa. O objetivo deste trabalho foi comparar variáveis de $\mathrm{FQ}$ de protocolos de Rorschach de pacientes psiquiátricos codificados pelo Sistema Compreensivo (SC) e pelo R-PAS. A amostra foi de 206 protocolos de Rorschach de pacientes adultos em tratamento psiquiátrico, que foram avaliados também pela SCID-I e SCID-II. A maioria dos protocolos foi aplicada pelo SC e recodificados de acordo com o R-PAS. O coeficiente kappa foi calculado, e foram comparadas as médias dessas variáveis nos dois sistemas. Os resultados do kappa variaram de concordância quase perfeita até consistência substancial para todas as variáveis, no entanto, as estatísticas descritivas confirmaram que o R-PAS provoca mais codificação de FQ ordinária e, o SC, de FQ menos.
\end{abstract}

Palavras-chave: avaliação psicológica, teste de Rorschach, técnicas projetivas, pacientes psiquiátricos

\section{Calidad Formal del Sistema Comprehensivo de Rorschach y R-PAS: Muestra de Casos Psiquiátricos}

\begin{abstract}
Resumen: La creación del Sistema de Evaluación del Desempeño de Rorschach (R-PAS) requiere estudios para su uso en la población brasileña. La calidad formal (FQ) es una categoría esencial en la clínica y la investigación. El objetivo del estudio fue comparar variables de FQ de protocolos de Rorschach codificados por el Sistema Comprehensivo y R-PAS. La muestra consistió de 206 protocolos de Rorschach de pacientes adultos en tratamiento psiquiátrico, que también fueron evaluados por la SCID-I y SCIDII. La mayoría de los protocolos fue aplicada en el SC y re-codificados de acuerdo con el R-PAS. Se calculó el coeficiente kappa y se comparó el promedio de estas variables en los dos sistemas. Los resultados de kappa se variaron desde concordancia casi perfecta hasta consistencia considerable para todas las variables, pero las estadísticas descriptivas confirmaron que el R-PAS provoca más codificación de FQ ordinaria y el SC de FQ menos.
\end{abstract}

Palabras clave: evaluación psicológica, test de Rorschach, técnicas proyectivas, pacientes psiquiátricos

\footnotetext{
${ }^{1}$ Support: São Paulo Research Foundation (FAPESP - Grant\#2011/02938-0), National Council for Scientific and Technological Development (CNPq Grant \# 303491/12013-2).

${ }^{2}$ Correspondence address:

Latife Yazigi. Rua Manoel Guedes, 385, apto. 11. CEP 04536-070. São

Paulo-SP, Brazil. E-mail: lyazigi@aclnet.com.br
}

Rorschach (1942/1981), referring to his Psychodiagnostics, conveyed that it was conceived from an experiment "consisting in the interpretation of accidental forms, that is, of non-specific forms" (p. 15), and that the inkblots needed to fulfill some gestalt requirements of the composition to prevent the figure from being rejected because 
it is regarded as "simply an ink-blot" (p. 15). Therefore, the crucial point of his method was "the chance forms" (p. 16) of the unstructured stimuli.

He explained that the interpretation of the figure is mainly determined by the form of the blot and that the individual, after looking at the blot, turns to himself to examine his own visual memories in order to find an image, that in its form matches the entire figure or part of it. Therefore, the form perception in the Rorschach test was since its beginning an important issue. We quote:

in order to avoid subjective evaluation statistical methods were used. Form answers given by a large number of normal subjects (100) were used as the norm and basis. From this a definite range of normal form visualization could be defined, and a large number of frequently recurring answers were collected. These were called 'good forms' $(F+)$ . . . those which are less clear are $F$-. (Rorschach, 1942/1981, p. 23)

He also provided data on the empirical relationships he found in clinical cases, such as that depressed mood increases the acuity of form perception, while excitement reduces it. Thus he noticed that good form answers involved the capacity to maintain attention throughout the test, and when this capacity is present clear perceptions are possible. According to him, good form answers involved four abilities (a) to maintain attention during the test, which involves an ability to concentrate that makes possible clear perceptions, (b) to have sharp engrams, (c) to recall into consciousness clear memory images, (d) to select the most fitting of the various similar images or engrams which result from looking at the stimuli. The last ability involves a complex associative process, which depends upon the attention which must now focus on both the external stimuli and the arising memory images or engrams as well. This functioning must, at the same time, furnish a control of the perceptive processes, and control criticism of the interpretation. However, the incorporated engrams also need both to be sharp, because if the recalled images are not exact, accurate form visualization will be difficult. Thus, "a high percentage of good forms presumes the ability to recall into consciousness, to "bring to mind' clear memory images" (Rorschach, 1942/1981, p. 57).

There must also be a capability to select the most fitting among the various similar images that arise. Therefore, attention must focus not only on the external figures, but on the storage memory images too. Consequently, this functioning should provide a control of the perceptive process as well as selfcriticism of the interpretations. The author concluded that when all these capacities are present 'to the maximum', the best forms ought to be seen in the protocols, and that the $F+\%$ reveals the clearness of certain associative processes, the length of the attention span, and the ability to concentrate. He considered that the optimum of these faculties is expressed from 80 to $95 \%$ of $\mathrm{F}+$. He found that the percentage of sharply perceived forms could be influenced by deliberate and conscious effort to do one's best in the test (Rorschach, 1942/1981).

According to Schachtel (1968) "Out of Chaos Form creates Kosmos" (p. 87), thus it is the most important aspect of the visible world. "From Aristotle and Plato to Thomas Aquinas, Leonardo, and Goethe form have been recognized as the ordering, structuring principle of the universe perceived by man" (p. 87). However, form must be flexible, transformational, and organizing.

Pure form perception is a construct which does not usually occur in the perception of our natural environment. It does occur in man's conceptualization of special relationships in geometry and trigonometry, and it is approximated in the manmade world of signs such as letters and numerals, and in some designs, especially diagrams. (Schachtel, 1968, p. 88)

He described that the function of form perception is to 'take hold' of features of the environment, and 'taking hold' requires an 'active perceptual attitude' that demands looking carefully instead of being passively 'struck' by something. Thus, it involves an active organization of the visual field in which

the eye and the mind have to pursue the dominant lines, form, and structure of the object which are its distinctive features; they have to take hold of these features, thus establishing a firm perceptual grasp of the object, so that it or its like can be found, seen, and recognized again and, to some extent, recalled at will. (Schachtel, 1968, p. 89)

According to him, in the Rorschach, "form perception has an adaptive function; it is related to reason, to man's rationality. And reason, certainly, is the most distinctive feature of man's - in contrast to the animal's - adaptation to and orientation in the world" (Schachtel, 1968, p. 90).

Exner (1974, 2003) built a Rorschach method, called A Comprehensive System, CS, based on five of the most important approaches: Beck, Hertz, Klopfer, Piotrowski, and Rappaport-Schafer. He sought to incorporate the best of each system into an integrated approach looking for a reliable method because he was deeply concerned with 'designed flaws or misjudged problems' in some Rorscharchers. A crucial issue he emphasized was that it was "often evaluated against orthodox psychometric standards even though it was not designed or interpreted in that context" (Exner, 2003, p. 6). To him, a system was needed that "would strengthen the use of the test and make it better prepared to stand the tests of reliability and validation" (p. 16).

In Exner (2001) 5th edition of his Rorschach Workbook for the Comprehensive System, the FQ working tables with a listing of responses is the latest revised one. He explained that the 'reference tables' reproduce the results gathered over more than 30 years and a substantial number of additions and updates were periodically made. He predicted that even though his system seemed 'as complete as possible', it will be

very likely that future research will lead to the development of new approaches to coding some type of responses, or the discovery of new variables or strategies that will enhance the interpretative yield of 
the test. In other words, it would be foolish to assume that the Comprehensive System has reached the last pinnacle in its development. (Exner, 2001, pp. V-VI)

In the CS there are four types of FQ: (1) OrdinaryElaborated $(+)$ an "unusually detailed articulation of form in responses that otherwise would be scored ordinary" (Exner, 2001, p. 47); (2) Ordinary (o) a common response in which form easily identifies an object, and "have been reported by at least $2 \%$ of persons in the FQ data pool for whole $[W]$ areas and for detail $[D]$ areas, or by at least 50 persons in the pool for unusual detail $[D d]$ areas" (p. 47); (3) Unusual (u) a low frequency response in which the basic contours are appropriated for response, answers that are seen quickly and easily by the observer; (4) Minus (-) a distorted, arbitrary, unrealistic answer which is "imposed on the blot structure with total disregard for the contours of the area" (Exner, 2001, p. 47). Finally, responses without any structure or form, such as ashes or blood, do not receive any FQ.

As to the compilation of the listing of FQ and of the normative tables, he wrote:

Nonpatient records used to create those samples were collected over a period of more than 10 years (1973 to 1986). As a number of records available increased, the tables were revised three times as various attempts to stratify the samples ensued. (Exner, 2003, p. 189)

In Brazil, there has been some relevant research on the normative data for the Rorschach in the CS. Nascimento (2007) collected 409 protocols of adult non-patient subjects, both genders, from urban and rural areas from the state of São Paulo, and compiled normative tables for all Rorschach CS variables; the author also built norms for 118 adolescents from the city of São Paulo (Nascimento, in press). Ribeiro, Semer, and Yazigi (2012) assessed 211 children of 7, 8, 9 and 10 years old, both genders, from public and private schools from the city of Cuiaba in order to construct normative data. Resende, Carvalho, and Martins (2012) presented separate norms age groups of 201 children and adolescent non-patients, aged 5-14 years, randomly selected from public and private schools divided into three age groups (5-7, 8-11, 12-14).

Villemor-Amaral, Yazigi, Nascimento, Primi, and Semer (2007) examined location areas and their respective FQ of 370 Brazilian non-patient adult subjects with a view to the construction of a Brazilian Atlas of specific Localization Areas with their respective FQ list. The validity studies on FQ in the CS in Brazil were: Marques, Chaves, and Yazigi (2012) who examined psychiatric patients and found that the $X A \%$ variable, which combines $F Q+, F Q o$ and $F Q u$, was sensitive to discriminate perceptual acuity in patients with psychotic features and non-psychotic patients, using both Exner's FQ listing (Exner, 1995/1999) and the Brazilian FQ listing (Villemor-Amaral et al., 2007). Pianowski and VillemorAmaral (2010) coded protocols on the FQ using both Exner $(1995 / 1999)$ and the Brazilian FQ listing (Villemor-Amaral et al., 2007) in a non-patient sample, and found that the Brazilian tables resulted in higher means for $F Q o, X A \%$ and
$X+\%$, and a lower mean for $F Q$-. Leonel, Semer, and Yazigi (2012) have also tested the FQ Brazilian list in a non-patient sample and found that $F Q o \%$ and $X+\%$ have higher means, while $F Q u, F Q-, X A \%, X u \%$ and $X-\%$ had lower means when using the Brazilian list. These studies provided evidence of the validity of the Brazilian FQ list.

The Rorschach Performance Assessment System R-PAS (Meyer, Viglione, Mihura, Erard, \& Erdberg, 2011) was developed from the CS (Exner, 2003). An important issue reviewed on the R-PAS was the development of FQ tables based on two elements, fit and frequency, which are considered as contributing to perceptual accuracy. Previously, Exner (1996) had offered an extensive discussion on the concept of critical stimulus bits in the Rorschach response process, which are visual features of the plates that contribute to the perceptual organization of the responses (Viglione, 2002), that is, why do things appear as they do? Why are certain responses given and why are certain responses not given?

Fit data were gathered by having judges rate how well more than 13,000 perceived objects fit the inkblot contours at specific inkblot locations using response objects from various prominent Rorschach specialists such as Beck, Hertz, Exner, Thomas, Small, Beizmann, which together include responses coded by Rorschach, Bohm, Klopfer, Loosli-Usteri, Binder, Bleuler, Oberholzer, and Rickers-Ovsiankina. All these perceived objects were listed and organized by location areas compiled by different sources and converted into a common set of designated areas. As to frequency, the R-PAS data were derived from five sets of adult FQ tables that were created in different countries such as Argentina, Brazil, Italy, Japan, and Spain, and specific frequency data for all Rorschach response objects that were reported by at least $1.5 \%$ of the people in each country's sample, except for Italy which used a $2.0 \%$ cut-off. The objects from each sample were translated into English and matching objects were linked to each one across samples and to all the objects that had been rated for fit. A modified list of objects included in the CS FQ tables (Exner, 2003) that had been modified before 2005 by members of Exner's Rorschach Research Council (RRC) to reduce irregularities, inconsistencies, obvious omissions, and redundancies was also included. This list contained 5,060 response objects with US-based FQ codes for the CS and it formed the basis for the objects to be listed in the current R-PAS FQ tables. Using a logical algorithm refined by initial data from several samples, the authors combined the fit, frequency, and historical FQ coding to determine revised FQ classifications for each object to be considered ordinary $(F Q o)$, unusual $(F Q u)$, or distorted $(F Q-)$. Ultimately, approximately $40 \%$ of the 5,060 objects have a different FQ designation in the R-PAS FQ tables than they did in the CS FQ tables. The R-PAS tables have about $5 \%$ fewer minus $(F Q-)$ and about $4 \%$ more unusual $(F Q u)$ codings (Meyer et al., 2011). In the R-PAS system the responses without any structure or form receive the code 'none' $(F Q n)$. The R-PAS FQ tables, therefore, seem to be more up to date and better adapted to the current times and more ample in the sense that they can be employed in different countries.

Hence, as we can see, the FQ of the response has been 
taken into consideration since the creation of the test by Hermann Rorschach, who emphasized the importance of this variable, and by the subsequent authors who supported and endorsed Rorschach's ideas; this is why FQ became part of ratios proportions, indexes and composite measures. For instance, the Thought and Perception Composite (TP-Comp) in the R-PAS, which was developed as the dimensional version of the Perceptual-Thinking Index (PTI), uses FQ as one of the main variables to identify the presence of thought disorders and psychotic-like condition. Also, the FQ interferes in such human representational responses, as Good Human and Poor Human Responses (GHR and PHR), that it tells about the interpersonal behaviors and their effectiveness, "patients with severe pathological disturbances give low frequencies of GHR answers" (Exner, 2003, p. 499), indicating the ability, or not, to "envision the self and relationships with others in an adaptive or positive way" (Meyer et al., 2011, p. 346). In the R-PAS, FQ is important in the Thought and Perception Composite (TP-Comp), an equivalent of the PTI, and related both to reality testing and thought disorganization. In the Ego Impairment Index (EII-2, EII-3), "a broad band measure of thinking disturbance and severity of psychopathology" (Meyer et al., 2011, p. 357), the FQ is also a fundamental variable. However, it is in the analysis of the human movement responses that the $\mathrm{FQ}$ is relevant, since $M$ - perceptions indicate severe distortions and disregard for the stimulus field (Exner, 2003). Consequently, those Rorschach indexes that include FQ play an important role not only in the clinical setting, in which they can support diagnosis and help to understand the distress of the individual and on the prognosis and better treatment planning, but also in the research context. In fact, several recent studies have tested the psychometric properties of these indexes (Mihura, Meyer, Dumitrascu, \& Bombel, 2013; Viglione, Giromini, Gustafson, \& Meyer, 2014; Wood, Garb, Nezworski, Lilienfeld, \& Duke, 2015), and applied them on several samples from different countries (DzamonjaIgnjatovic, Smith, Djuric Jocic, \& Milanovic, 2013; Moore, Viglione, Rosenfarb, Patterson, \& Mausbach, 2013; Silva \& Costa, 2014). Valkonen, Lindfors, and Knekt (2012) used the Ego Impairment Index, EII, to study anxiety disorders, and found a significant, but weak association between the $E I I$ and the interview-based scale Level of Personality Organization, LPO, (Pyykkönen, 2008, apud Valkonen et al., 2012). Conversely, Rosenbaum, Andersen, Knudsen, and Lorentzen (2012), in a follow-up study with admitted patients with firstepisode of schizophrenia, found that the PTI did not show significant changes after two years of treatment, in spite of other instruments that did. Benedik, Čoderl, Bon, and Smith (2013) tested the PTI with the purpose of distinguishing psychotic from nonpsychotic psychiatric inpatients, and did not find differences within the groups in their sample.

Based on the literature, it seems that the CS and R-PAS tables provide different estimations of FQ for adult samples. Due to the limited research with the R-PAS using psychiatric patients in Brazil, it is not clear whether the CS and R-PAS tables provide different estimates of FQ for this group of subjects. So, the present research arose from the idea of comparing the CS and R-PAS on the FQ assigned to the
Rorschach responses of a Brazilian psychiatric case sample.

It is an exploratory and naturalistic study in a clinical setting (Fonagy \& Kächele, 2009) that the sample was intentional stratified due to the intentional and categorical selection of the chosen individuals (Patton, 2002). The proposal was to observe if there were differences between the $\mathrm{CS}$ and the R-PAS in their process of coding the FQ of each Rorschach response and in each protocol. They employed the CS list of FQ and the R-PAS list, which includes FQ responses from five countries (international reference sample). Therefore, the hypothesis is that the R-PAS FQ table will be closer to the fit condition of the international sample.

\section{Method}

\section{Participants}

The participants were patients treated in psychotherapy in an outpatient public service. They were referred by different university hospital clinics and attended the treatment voluntarily. These individuals, after the psychiatric triage, and after being accepted for psychotherapy, were invited to participate in the study on psychotherapy outcome. They were submitted to psychological assessment but were allowed to not accept the evaluation. The sample was comprised of 206 subjects who were psychiatric cases, being 152 (74\%) women; the age varied from 18 to 72 years old (mean and median of 39 years old); the schooling varied from 0 to 23 years (mean and median of 11 years). The majority of individuals (64.5\%) showed depressive symptoms on Axis-I, while on Axis-II Personality Disorders predominated (67.0\%), mainly from Cluster B (borderline, narcissistic, histrionic, and antisocial: $40.3 \%$ ), followed by Cluster C (avoidant, dependent, obsessive-compulsive: $26.7 \%$ ).

The inclusion and exclusion criteria were established by the team of supervisors as an indication to the psychotherapy. The inclusion criteria were to have at least 18 years of age and interest and availability to come to the therapeutic sessions; the exclusion criteria were the presence of schizophrenic or antisocial troubles, dementia or mental retardation.

\section{Instruments}

The instruments were the DSM Structured Clinical Interviews for Axis-I (SCID-I) and Axis-II (SCID-II) and Rorschach, both CS (Exner, 2003) and R-PAS (Meyer et al., 2011). The Portuguese version for SCID was translated and validated by Del-Ben et al. (2001). The use of structured interviews enhances the diagnosis reliability and standardizes the evaluation process, better than using just clinical diagnosis.

\section{Procedure}

Data collection. The database is from a study on psychotherapy outcome in which the subjects were assessed by the Rorschach CS in annual follow-ups. From this database, Rorschach protocols taken upon admission to 
therapy were selected. These are protocols of individuals referred to psychotherapy by different clinics of the school hospital and assessed by the SCID-I and SCID-II to the psychiatric diagnoses, by psychiatrists who were staff members of the Department of Psychiatry with experience using the instruments. Software for the Brazilian validated version of both interviews was created specifically for the psychotherapy outcome research.

The Rorschach was administered and coded according to the CS for the majority of subjects. At the present time, previous protocols were re-coded and new 43 protocols were administrated according to the R-PAS. To accommodate the change from CS to R-PAS only the first four responses were used from all cards of all protocols. The FQ List of each system was employed to code each response, thus Exner (1995/1999), and Meyer et al. (2011). Each protocol was then entered in the R-PAS online software as separate cases for each subject coded by each FQ system, CS and R-PAS. The Rorscharchers in charge of coding the protocols for the CS was composed of five skilled psychologists with 5 to 15 years of practice on the CS.

Data analysis. A senior Rorscharcher coded the 206 protocols in the R-PAS. Following Meyer's request (personal communication), $51.0 \%$ of them (105 protocols) were divided among three Rorscharchers in order to recode the responses using the R-PAS FQ tables while blind to the original coding in the CS. The $F Q+$ of the CS was codified as $F Q o$. A reliability study on the R-PAS FQ was completed in which 10 protocols were randomly selected from each recorder to form a pool of 30 records, which were then coded by an external judge with 13 years of training in the CS. The external judge was also blind to all previous codings.
Due to the tendencies of higher $F Q \circ \%$ on the R-PAS and higher $F Q-\%$ on the CS, a comparison was carried out between R-PAS and CS on $F Q \circ \%, F Q u \%, F Q-\%$, and also on $X A \%$ (the sum of FQ coding,$+ o$, or $u$ divided by the number of responses $[R])$, and $W D A \%(W+D$ related concerns the sum of FQ coding ,$+ o$, or $u$ divided by $W+D$ ) at the protocol level using a paired t-test with Cohen's $d$ as the effect size statistic computed from the mean and standard deviations of each variable.

\section{Ethical Considerations}

All the participants signed an agreement accepting to take part in this study. The research was approved by the Ethics Committee of the Universidade Federal de São Paulo (no. 0758/02) on September 23, 2002.

\section{Results}

As to the reliability study, the results were satisfactory due to kappa $=.798$. The interclass correlation coefficient (ICC) was also calculated for the variables at protocol level. Therefore, there were two levels of data; one considered the response level (4,612 responses) and another considered the protocol level (206 protocols). At the protocol level, the results to average measures were $F Q o \%=.94, F Q u \%=$ $.87, F Q-\%=.91$, and $F Q n o n e=.95$. The kappa coefficient was used to compare the FQ coding of the responses in the CS with those of R-PAS. The results are displayed in Table 1. At the response level, out of 4,612 responses, the kappa coefficient between the CS and R-PAS as to the FQ variables $F Q o, F Q u, F Q-$, and $F Q n$ was of substantial consistency of classification (.759).

Table 1

Comparison of FQ Coding Using CS and R-PAS Guidelines at the Response Level Across All Ten Cards $(\kappa=.759)$

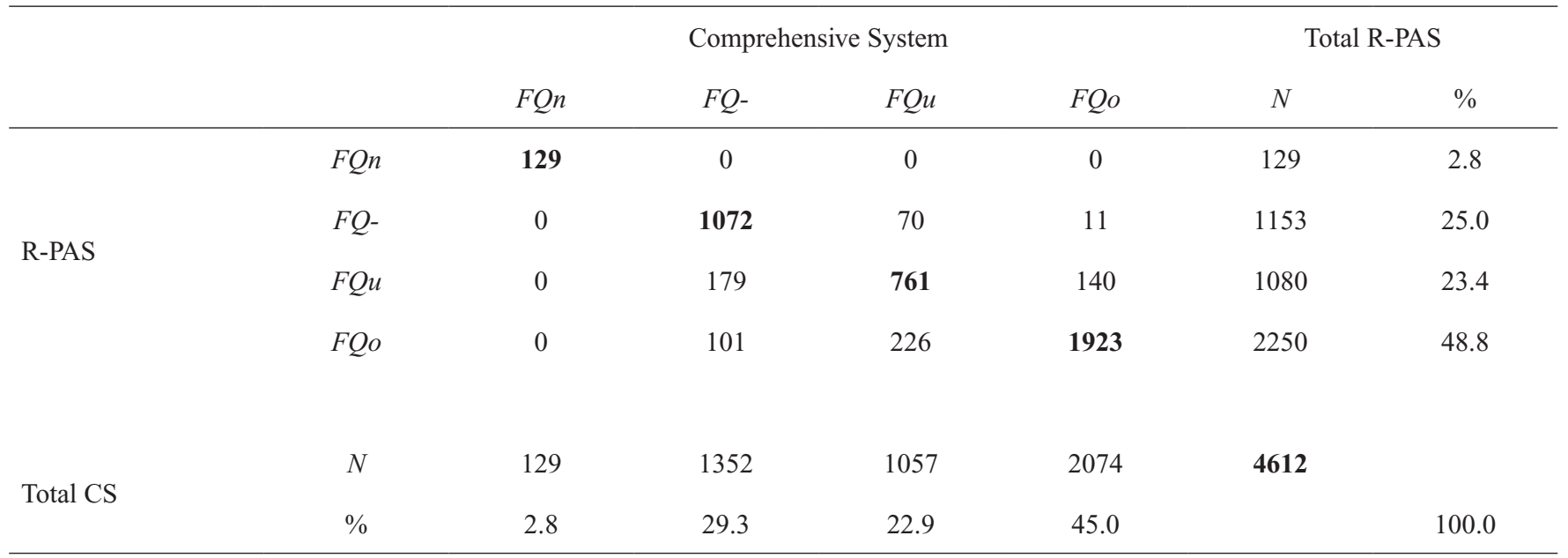

Note. FQn = FQnone. The values in boldface show when the $F Q$ remains the same on both systems.

As to the comparison carried out between R-PAS and $\mathrm{CS}$ on $F Q o \%, F Q u \%, F Q-\%, X A \%$, and $W D A \%$, the results are displayed in Table 2 . These results corroborate the trend pointed out above which shows significant differences between both systems as to the $F Q o \%$ and
$F Q-\%$, with the R-PAS showing a higher mean on $F Q o \%$ $(d=.29), X A \%(d=.34), W D A \%(d=.28)$, and the CS higher mean on $F Q-\%(d=.35)$ which confirms the results obtained at response level. These differences produced medium effect sizes. 
Table 2

Descriptive Statistics, Paired t-Tests, and Cohen's d Values Comparing the Means of the FQ Variables According to R-PAS and CS Coding at the Protocol Level

\begin{tabular}{|c|c|c|c|c|c|c|c|c|}
\hline & & $M$ & $M d n$ & $S D$ & $\begin{array}{c}\text { Paired } \\
t \text {-test }\end{array}$ & $d f$ & $p$ & Cohen's $d$ \\
\hline \multirow[t]{2}{*}{$F Q o \%$} & R-PAS & 49.7 & 50.0 & 13.43 & 7.500 & 205 & $<.001$ & .29 \\
\hline & $\mathrm{CS}$ & 45.8 & 45.0 & 13.32 & & & & \\
\hline \multirow[t]{2}{*}{$F Q u \%$} & R-PAS & 23.3 & 24.0 & 10.24 & .765 & 205 & .445 & .04 \\
\hline & $\mathrm{CS}$ & 22.9 & 22.0 & 10.89 & & & & \\
\hline \multirow[t]{2}{*}{$F Q-\%$} & R-PAS & 24.1 & 23.5 & 12.10 & -9.344 & 205 & $<.001$ & -.35 \\
\hline & $\mathrm{CS}$ & 28.4 & 28.0 & 12.80 & & & & \\
\hline \multirow[t]{2}{*}{$X A \%$} & R-PAS & .73 & .75 & .13 & 9.379 & 205 & $<.001$ & .34 \\
\hline & $\mathrm{CS}$ & .69 & .69 & .13 & & & & \\
\hline \multirow[t]{2}{*}{$W D A \%$} & R-PAS & .65 & .65 & .14 & 8.668 & 205 & $<.001$ & .28 \\
\hline & $\mathrm{CS}$ & .61 & .61 & .14 & & & & \\
\hline
\end{tabular}

Note. Cohen's $d$ was computed directly from the observed $M \mathrm{~s}$ and $S D$ s and thus the effect size was not increased as a function of the correlation between paired observations.

An examination of relative "card difficulty" (expression from Herman Rorschach) by R-PAS coding is given in Table 3, where each card is listed in descending order on $F Q o \%$ and in ascending order on $F Q-\%$. On the one hand, looking at the table, we can see that Cards V, I and III are those with higher values of $F Q o \%$ and the lowest scores on $F Q-\%$, which means that these cards elicit more accurate perceptions and less distorted perceptions. On the other hand, Cards VI, X and IX are those with higher values on $F Q-\%$ and lowest scores on $F Q o \%$, meaning that these cards elicit more inaccurate and less precise perceptions.

Table 3

Relative Card Difficulty Indicated by the Rank Ordering of Cards According to R-PAS Values With FQo\% Listed in Descending Order and FQ-\% Listed in Ascending Order

\begin{tabular}{lcccc}
\hline Order & Card & $F Q o \%$ & Card & $F Q-\%$ \\
\hline 1st & V & 73.6 & V & 10.7 \\
2nd & I & 59.4 & I & 17.1 \\
3rd & III & 57.0 & III & 19.7 \\
4th & VII & 54.0 & IV & 21.8 \\
5 th & IV & 53.5 & VII & 23.1 \\
6th & II & 53.3 & II & 24.1 \\
7 th & VIII & 50.1 & VIII & 24.4 \\
8th & VI & 34.5 & VI & 26.0 \\
9 th & X & 34.5 & X & 34.5 \\
10th & IX & 20.8 & IX & 45.8 \\
\hline
\end{tabular}

\section{Discussion}

The FQ is one of the most important variables in the Rorschach due to its relation with perception accuracy and therefore to reality testing and ego functioning. Rorschach (1942/1981) emphasized this importance when he stressed that the interpretation of the form belonged to the field of perception rather than imagination, in which the effort to integrate the image is realized consciously as an effort, and he concludes that the experiment could be called "a test of the perceptive power of the subject" (p. 18). In a metaanalysis review on the Rorschach CS variables, Mihura et al. (2013) found that the variables that provided the strongest empirical support were those related to perceptual processes. The importance of the FQ in the Rorschach can be measured by the fact that each response has to be checked as to its FQ accuracy, taking as reference the general population perceptions listed in the tables. The FQ of the responses is part of some R-PAS indexes such as GHR and PHR, EII-3, TP-Comp, SC-Comp, Complexity, FQo\%, FQu\%, FQ-\%, $M-$, and $W D-\%$.

For this reason, in the task of assessing psychotherapy outcome, $F Q$ is an important issue to be analyzed, mainly in a group with severe psychiatric symptoms since the adequacy of the form perception is an indicator of the integrity of ego functioning. Korchin and Larson (1977) considered the final Rorschach response not just a "defined perceptual act", but an outcome of a "coordinated series of cognitive activities in a total process of forming, testing, critically evaluating, and communicating perceptual hypotheses" (p. 160). The purpose of employing the new R-PAS system led us to take into consideration the changes in FQ coding as a crucial concern. This was the main reason for this study.

In the chapter "Comparing the R-PAS and the Rorschach 
CS FQ tables" of the R-PAS Manual (Meyer et al., 2011), the authors asserted that there are considerable differences between the R-PAS and RRC-modified CS classification (made by the Rorschach Research Council) of objects. Out of 5,060 entries, 39.9\% showed different FQ designations while $60.1 \%$ were the same, therefore they found a low level of agreement between the entries contained in the two tables $(\kappa=.375)$, with the R-PAS FQ tables having about $5 \%$ fewer $F Q$ - designations and about $4 \%$ more $F Q u$ designations (p. 425). According to the authors, when the same normative protocols were scored using both sets of tables and the results compared, the greatest difference was found on $F Q-\%$ with higher values on the CS, though differences were also observed on $F Q o \%$ and $F Q u \%$, both of which were higher according to the R-PAS coding. In a previous study, the authors (Meyer, Erdberg, \& Shaffer, 2007), when discussing the International CS References Samples, remarked that the frequency of the $F Q$ - were higher than in the US in almost all the 16 countries, with $20 \%$ of the responses coded as $F Q$ when the SC criteria was employed.

Cardoso (2012), in Brazil, compared the Rorschach performance of 30 psychiatric patients, psychotic, and 28 non-patients, adults, and both genders. The Rorschach was administrated according to the CS (Exner, 2003) and the responses were coded according to the CS listing of FQ (Exner, 1995/1999), to the R-PAS FQ tables (Meyer et al., 2011), and to the Brazilian location and FQ list (VillemorAmaral et al., 2007). The comparison among coding models pointed to significant differences, besides others, in $F Q o$, $F Q u, X u \%, X-\%$ and $X A \%$ variables. The psychotic group showed an increased $F Q$ - and $X-\%$ and reduced $F Q o, F Q u$, $X u \%$ and $X A \%$ as expected. The author concluded that the results indicated that the three models were sensitive enough to differentiate the two compared groups.

Cardoso (2012) results coincide with those of the present study that showed substantial agreement between the CS and R-PAS on $F Q n, F Q-, F Q u$, and $F Q o$ when the comparison was at the response level $(\kappa=.759)$, however, at the protocol level, the results confirm a difference between both systems on $F Q o$ and on $F Q$-, with R-PAS showing higher values on $F Q o$ while the CS showing higher values on $F Q$-. These findings from a sample of outpatients in Brazil replicate the non-patient U.S. findings reported in the R-PAS manual on $F Q-\%$ and $F Q o \%$, though not on $F Q u \%$; thus we can say that the R-PAS captures better than the CS the population's tendency in recognizing the most common or realistic perceptions.

Another interesting piece of data was that the R-PAS highest scores of $F Q o \%$ were found on cards V, I and III while the highest $F Q-\%$ scores were found on cards VI, $\mathrm{X}$ and IX. It is fascinating to correlate these data with Rorschach (1942/1981) descriptions of these cards. Thus, as to the FQo cards, he writes, Plate V: "Black. The easiest form to interpret. Almost always interpreted as a 'bat', or 'a 'moth"; Plate I: "Black. Failure is almost never encountered. . . . Easy to interpret as a Whole and in Details"; Plate III: "Black and Red. Kinesthesia's easiest to see". As to the $F Q$ - cards, Plate VI: "Black. Generally called the most difficult of the figures";
Plate X: "Multicolored. Disparate blots. Whole answers almost impossible"; Plate IX: "Multicolored. Discordant color and form" (Rorschach, 1942/1981, p. 52). How current the Rorschach's comments on the cards' gestalt are.

Summarizing, it was found that the R-PAS elicits more FQ ordinary coding while the CS elicits more FQ minus coding. Therefore, whilst we can get more ordinary FQ using the R-PAS, there is no difference using one or other system. Nevertheless, the CS tends to code more $F Q$ - than the R-PAS, and in the present study we noticed that some $F Q$ - responses in the CS were scored $F Q u$ in the R-PAS.

On the R-PAS, $F Q$ is based in two elements: Fit and frequency. Meyer et al. (2011) also compared responses coded according to the CS and to the R-PAS FQ tables, and found that $60.1 \%$ of the responses have the same FQ code in the two systems, and the FQ tables of R-PAS have 5\% fewer $F Q$ - scorings. However, the authors concluded that both systems produce valid results.

Hence, it is imperative to continue researching the FQ of the Rorschach responses as well as testing whether different coding systems can produce different results in a same sample. However, examining this way Exner (2003, pp. 377-378) stated that:

All minus answers do not reflect the same level of disregard for reality. The vast majority of minus responses include some features that are congruent with elements of the stimulus field. The location is reasonably precise and, even though the response is coded minus, some components of it can be identified rather easily ... A more serious type of minus is the answer that, for the most part, has a good form fit but is coded minus because it has been spoiled by the addition of a significant component that is clearly inappropriate. For example, a card III response of 'two men ( $D 9$ 's) beating on the head of a woman $(D 7)$ '. The identification of $D 9$ as a human figure is appropriate and popular, but the $D 7$ area as a human head is clearly minus.

In a conversation with G. Meyer (by e-mail, who kindly agreed with the transcription of his comments), it was possible to observe the difference in FQ coding. For instance, a patient's answer to card II: " $V$ this looks like a person as if I was looking at him from behind and as if he was crawling. Inq: Look the feet here (D2), then, looking from behind (DS5), the bottom (on D6), as if the legs are bent and he is crawling. Here the head (D3), disheveled, and the hands are here touching the floor (red blots in D1). You can see until the knee, but not the part of the thigh until the hip. Here the feet, ankle, shin, and here the knee, this hidden little red spot". We and the external judge have coded this answer as $F Q$ - in both CS and R-PAS. We quote G. Meyer that considered this answer on the edge of $F Q u$ and $F Q$-. He wrote:

The tables do not provide good reference points to guide extrapolation from the listed objects to this object. There is nothing relevant in the $W$ area. In $D 2$, we see "Sock" is $F Q o$ and this could be used to 
extrapolate to the "foot" in this response. In $D 3$ we see "Head (Devil or Monster)" as FQu which has a relevant link to the 'disheveled head' in this percept, if I am correct in understanding that the term 'disheveled' is used to account for the projections in the $D d 25$ area that otherwise do not fit an image of a head. So we have some guidance from the tables that suggest parts of the percept are likely coded $F Q o$ or $F Q u$. But we still need to consider the composite image and to what extent the two reference points from the tables form 'critical bits' for this percept. It thus becomes an "examiner judgment" decision, though with a leaning away from $F Q$ - given the two tables entries. With a response requiring examiner judgment, the critical decision comes down to making a judgment using the Form Accuracy rating scale given on p. 179 of the manual [Meyer et al., 2011] while looking at the inkblot. For $F Q u$ versus $F Q$ - the critical decision is whether you judge the response to be more like "Not really. I don't really see that. Overall, it does not match the blot area." or "A little. If I work at it, I can sort of see that." If the former, code $F Q$-; if the latter, code $F Q u$. For this response, I would come down on the side of $F Q u$. (G. Meyer, personal communication, 2014 May 15).

As we could see, the CS and the R-PAS have different ways based on different strategies on coding the $F Q$ - and $F Q u$.

This study had some limitations because it only examined the relative impact of the different tables on the coded responses. Other possible analysis from this clinical material could be to compare the protocols from subjects with different psychopathological diagnosis viewing the FQ and the reality test, the perception distortion, and their importance in the differential diagnosis. In addition, we scored protocols previously administrated using the CS. Nevertheless, it confirmed that we can consult the CS or the R-PAS tables interchangeably, however, the better it would be to use the R-PAS tables because of its tendency to identify more $F Q o$ and less $F Q$-perceptions than the CS, and because it encompasses the Form Quality lists of five countries including Brazil.

\section{References}

Benedik, E., Čoderl, S., Bon, J., \& Smith, B. L. (2013). Differentiation of psychotic from nonpsychotic psychiatric inpatients: The Rorschach Perceptual Thinking Index. Journal of Personality Assessment, 95(2), 141-148. doi: 10.1080/00223891.2012.753898

Cardoso, L. M. (2012). Comparação da sensibilidade de três listas de qualidade formal para avaliação de psicopatologia no Rorschach [Comparison of sensitivity of three form quality lists on Rorschach psychopathological evaluation] (Unpublished doctoral dissertation). Universidade São Francisco, Itatiba, SP.

Del-Ben, C. M., Vilela, J. A. A., Crippa, J. A. S., Hallak, J. E. C., Labate, C. M., \& Zuardi, A. W. (2001). Confiabilidade da "Entrevista Clínica Estruturada para o DSM-IV Versão Clínica" traduzida para o português [Reliability of the Structured Clinical Interview for DSM-IV - Clinical version translated into Portuguese]. Revista Brasileira de Psiquiatria, 23(3), 156-159. doi:10.1590/S151644462001000300008

Dzamonja-Ignjatovic, T., Smith, B. L., Djuric Jocic, D., \& Milanovic, M. (2013). A comparison of new and revised Rorschach measures of schizophrenic functioning in a Serbian clinical sample. Journal of Personality Assessment, 95(5), 471-478. doi:10.1080/00223891.201 3.810153

Exner, J. E., Jr. (1974). The Rorschach: A Comprehensive System: Vol. 2. Interpretation. New York, NY: Wiley.

Exner, J. E., Jr. (1996). Critical bits and the Rorschach response process. Journal of Personality Assessment, 67(3), 464-477. doi:10.1207/s15327752jpa6703_3

Exner, J. E., Jr. (1999). Manual de classificação do Rorschach para o Sistema Compreensivo [A Rorschach workbook for the Comprehensive System] (A. C. P. Silva Neto, Trans.). São Paulo, SP: Casa do Psicólogo. (Original work published 1995)

Exner, J. E., Jr. (2001). A Rorschach workbook for the Comprehensive System (5th ed.). Asheville, NC: Rorschach Workshops.

Exner, J. E., Jr. (2003). The Rorschach: A Comprehensive System: Vol. 1. Basic foundations and principles of interpretation (4th ed.). Hoboken, NJ: John Wiley \& Sons.

Fonagy, P., \& Kächele, H. (2009). Psychoanalysis and other long-term dynamic psychotherapies. In M. G. Gelder, J. J. Lopez Ibor, \& N. Andreasen (Eds.), New Oxford textbook of psychiatry (2nd ed., Vol. 2, pp. 1337-1349). Oxford, UK: Oxford University Press.

Korchin, S. J., \& Larson, D. G. (1977). Form perception and ego functioning. In M. A. Rickers-Ovsiankina (Ed.), Rorschach psychology (pp. 159-187). New York, NY: R. E. Krieger.

Leonel, J. C., Semer, N. L., \& Yazigi, L. (2012). Estudo brasileiro de validação para localização e lista de qualidade formal do Rorschach-SC: Não pacientes psiquiátricos [Brazilian validation study to locate and list of formal quality of the Rorschach-CS: Non-psychiatric patients]. Psico-USF, 17(1), 119-127. doi:10.1590/ S1413-82712012000100013

Marques, T. C., Chaves, A. C., \& Yazigi, L. (2012). Estudo parcial da validação do atlas do Rorschach Sistema Compreensivo em amostra de pacientes psiquiátricos de São Paulo [Partial validation study of the Rorschach Comprehensive System atlas on a sample of psychiatric patients of São Paulo]. Psico-USF, 17(3), 417-426. doi:10.1590/S1413-82712012000300008

Meyer, G. J., Erdberg, P., \& Shaffer, T. W. (2007). Toward international normative reference data for the Comprehensive System. Journal of Personality Assessment, 89(Suppl. 1), S201-S216. doi:10.1080/00223890701629342

Meyer, G. J., Viglione, D. J., Mihura, J. L., Erard, R. E., \& Erdberg, P. (2011). Rorschach performance assessment 
system: Administration, coding, interpretation, and technical manual. Toledo, OH: Rorschach Performance Assessment System.

Mihura, J. L., Meyer, G. J., Dumitrascu, N., \& Bombel, G. (2013). The validity of individual Rorschach variables: Systematic reviews and meta-analyses of the Comprehensive System. Psychological Bulletin, 139(3), 548-605. doi:10.1037/a0029406

Moore, R. C., Viglione, D. J., Rosenfarb, I. S., Patterson, T. L., \& Mausbach, B. T. (2013). Rorschach measures of cognition relate to everyday and social functioning in schizophrenia. Psychological Assessment, 25(1), 253263. doi: $10.1037 / \mathrm{a} 0030546$

Nascimento, R. S. G. F. (2007). Rorschach Comprehensive System data for a sample of 409 adult nonpatients from Brazil. Journal of Personality Assessment, 89(Suppl. 1), S35-S41. doi:10.1080/00223890701582905

Nascimento, R. S. G. F. (in press). Rorschach: Normas para adolescentes em diferentes etapas da vida [Rorschach: Norms for adolescents in different life stages] Psicologia: Teoria e Pesquisa.

Patton, M. Q. (2002). Qualitative research \& evaluation methods (3rd ed.). Thousand Oaks, CA: Sage.

Pianowski, G., \& Villemor-Amaral, A. E. (2010). Localização e qualidade formal do Rorschach no Brasil: Validade com não pacientes [Location and formal quality of the Rorschach-SC in Brazil: Validity with non-patient sample]. Psico-USF, 15(3), 333-343. doi:10.1590/S141382712010000300007

Resende, A. C., Carvalho, T. C. R., \& Martins, W. (2012). Desempenho médio de crianças e adolescentes no método de Rorschach Sistema Compreensivo [Average performance of children and adolescents in Rorschach Comprehensive System]. Avaliação Psicológica, 11(3), 375-394.

Ribeiro, R. K. S. M., Semer, N. L., \& Yazigi, L. (2012). Rorschach Comprehensive System data from a sample of 211 nonpatient children in Brazil. Journal of Personality Assessment, 94(3), 267-275. doi:10.1080/00223891.201 1.653727

Rorschach, H. (1981). Psychodiagnostics. Bern, Switzerland: Hans Huber. (Original work published 1942)

Rosenbaum, B., Andersen, P. B., Knudsen, P. B., \& Lorentzen, P. (2012) Rorschach inkblot method data at baseline and after 2 years treatment of consecutively admitted patients with first-episode schizophrenia. Nordic Journal of Psychiatry, 66(2), 79-85. doi:10.3109/08039488.2011.5 95500

Schachtel, E. G. (1968). Experiential foundation of the Rorschach's test. New York, NY: Basic Books.

Silva, H. C. S. R., \& Costa, I. I. (2014). Rorschach e sofrimento psíquico grave: Funcionamento psíquico nas primeiras crises psicóticas [Rorschach and severe psychic suffering: Psychic functioning in first psychotic crisis]. Estudos de Psicologia (Campinas), 31(3), 337-345. doi:10.1590/0103-166X2014000300002

Valkonen, H., Lindfors, O., \& Knekt, P. (2012). Association between the Rorschach Ego Impairment Index and the Level of Personality Organization Interview assessment in depressive and anxiety disorder patients. Psychiatry Research, 200(2-3), 849-856. doi:10.1016/j. psychres.2012.05.012

Viglione, D. J. (2002). Rorschach coding solutions. San Diego, CA: Trading Printing Services.

Viglione, D. J., Giromini, L., Gustafson, M. L., \& Meyer, G. J. (2014). Developing continuous variable composites for Rorschach measures of thought problems, vigilance, and suicide risk. Assessment, 21(1), 42-49. doi: $10.1177 / 1073191112446963$

Villemor-Amaral, A. E., Yazigi, L., Nascimento, R. S. G. F., Primi, R., \& Semer, N. L. (2007). Localização, qualidade formal e respostas populares do Rorschach no CS em uma amostra brasileira [Location, form quality and popular responses of Rorschach CS in a Brazilian sample, Abstract]. Work presented at the Terceiro Congresso Brasileiro de Avaliação Psicológica, João Pessoa, PB.

Wood, J. M., Garb, H. N., Nezworski, M. T., Lilienfeld, S. O., \& Duke, M. C. (2015). A second look at the validity of widely used Rorschach indices: Comment on Mihura, Meyer, Dumitrascu, and Bombel (2013). Psychological Bulletin, 141(1), 236-249. doi:10.1037/a0036005

Latife Yazigi is an Affiliated Professor of the São Paulo School of Medicine, Universidade Federal de São Paulo.

Norma Lottenberg Semer is an Affiliated Professor of the São Paulo School of Medicine, Universidade Federal de São Paulo.

Maria Luiza de Matos Fiore is a Psychiatrist of the São Paulo School of Medicine, Universidade Federal de São Paulo.

Roberta Katz Abela is a Psychologist of the São Paulo School of Medicine, Universidade Federal de São Paulo.

Tatiana Gottlieb Lerman is a Psychologist of the São Paulo School of Medicine, Universidade Federal de São Paulo.

Thais Cristina Marques is a Professor of the Universidade Anhembi Morumbi.

Received: Feb. 12, 2015

1st Revision: July 17, 2015

Approved: Aug. 28, 2015

How to cite this article:

Yazigi, L., Semer, N. L., Fiore, M. L. M., Abela, R. K., Lerman, T. G., \& Marques, T. C. (2016). Form quality in Rorschach Comprehensive System and R-PAS: Sample of psychiatric cases. Paidéia (Ribeirão Preto), 26(63), 53-61. doi:10.1590/1982-43272663201607 